\title{
Electroporation of Intracellular Liposomes Using Nanosecond Electric Pulses-A Theoretical Study
}

\author{
Lea Retelj, Gorazd Pucihar, and Damijan Miklavčič*
}

\begin{abstract}
Nanosecond (ns) electric pulses of sufficient amplitude can provoke electroporation of intracellular organelles. This paper investigates whether such pulses could provide a method for controlled intracellular release of a content of small internalized artificial lipid vesicles (liposomes). To estimate the pulse parameters needed to selectively electroporate liposomes while keeping the plasma and nuclear membranes intact, we constructed a numerical model of a biological cell containing a nucleus and liposomes of different sizes (with radii from 50 to $500 \mathrm{~nm}$ ), which were placed in various sites in the cytoplasm. Our results show that under physiological conditions selective electroporation is only possible for the largest liposomes and when using very short pulses (few ns). By increasing the liposome interior conductivity and/or decreasing the cytoplasmic conductivity, selective electroporation of even smaller liposomes could be achieved. The location of the liposomes inside the cell does not play a significant role, meaning that liposomes of similar size could all be electroporated simultaneously. Our results indicate the possibility of using ns pulse treatment for liposomal drug release.
\end{abstract}

Index Terms-Electroporation, finite-element model, liposomes, nanosecond (ns) electric pulses.

\section{INTRODUCTION}

$\mathbf{E}$ XPOSING the cell to an external electric field causes accumulation of charges on both sides of the plasma membrane and consequently the formation of an induced transmembrane voltage (ITV) [1], [2]. If ITV reaches a certain value $(\sim 0.2-$ $1 \mathrm{~V})$, membrane permeability increases, allowing molecules for which the plasma membrane is under physiological conditions poorly permeable to enter or exit the cell [2]-[4]. Theories supported by molecular dynamics simulations suggest that the observed increase in membrane permeability results from the formation of hydrophilic pores in the lipid bilayer, which

Manuscript received January 12, 2013; revised March 25, 2013 and April 22, 2013; accepted May 1, 2013. Date of publication May 7, 2013; date of current version August 16, 2013. This work was supported by the Slovenian Research Agency. Research was conducted within the scope of the European Associated Laboratory for Pulsed Electric Field Applications in Biology and Medicine (LEA EBAM). Asterisk indicates corresponding author.

L. Retelj is with the Faculty of Electrical Engineering, University of Ljubljana, Ljubljana SI-1000, Slovenia (e-mail: lea.retelj@fe.uni-lj.si)

G. Pucihar, deceased, was with the Faculty of Electrical Engineering, University of Ljubljana, Ljubljana SI-1000, Slovenia (e-mail: gorazd.pucihar@fe.uni1j.si).

*D. Miklavčič is with the Faculty of Electrical Engineering, University of Ljubljana, Ljubljana SI-1000, Slovenia (e-mail: damijan.miklavcic@ fe.unilj.si).

Color versions of one or more of the figures in this paper are available online at http://ieeexplore.iee.org.

Digital Object Identifier 10.1109/TBME.2013.2262177 gives the phenomenon its name-electroporation [5]-[8]. When the electric field is not too strong and the exposure is not too long, the pores reseal in seconds to minutes after exposure and the cells restore their normal activity. Today, electroporation is commonly used in many fields of biology, biotechnology, and medicine, for applications such as cell fusion [9], [10], electrochemotherapy [11]-[14], gene electrotransfer [15]-[17], food processing [18], [19], and others.

In "classical" electroporation, rectangular pulses of microor milli-second duration with rise times in the order of $\mu \mathrm{s}$ and amplitudes in the range of kilovolt per centimeter are used. As the charging time of a cell is typically much shorter than the pulse duration (for a cell with radius of $\sim 10 \mu \mathrm{m}$ the charging time in physiological medium is in the order of $100 \mathrm{~ns}$ ), classical electroporation pulses primarily affect the plasma membrane while the cell interior practically remains shielded from the external electric field. However, if the cells are exposed to pulses with duration in the nanosecond range and amplitudes of several tens of kilovolts per centimeter, a high electric field is also present in the cell interior and affects the membranes of cell organelles [20]. Nanosecond (ns) pulses were reported to permeabilize intracellular granules [21], large endocytosed vacuoles [22], endocytotic vesicles [23], the nuclear envelope [24], the inner mitochondrial membrane [25], and also stimulate the release of calcium from endoplasmic reticulum [26]-[28].

The effects of ns pulses are primarily nonthermal. When pulses are applied in the moderate number, the overall increase in the temperature of the pulsed sample is practically negligible due to short pulse duration [29]. Yet, recent modeling results suggest that considerable temperature increases could indeed occur at local membrane sites and contribute to the observed biophysical responses of cells [30].

The feasibility of intracellular organelle electroporation motivated us to study the possibility of using ns pulses for selective electroporation of intracellular artificial lipid vesicles (liposomes). Liposomes present a convenient way to deliver various solutions containing drugs, proteins, or nucleic acids into cells, as they protect their content from the hostile environment (e.g., nucleic acids from endogenous nucleases in the blood plasma), reduce the toxicity of the containing drug for the nontargeted cells, increase the uptake of the drug into the targeted cells and consequently increase the drug efficacy [31], [32]. We hypothesize that when the liposomes reach the cell interior, ns pulses could provide a method for a controlled release of their content into the cytosol.

Recently, attention has been devoted to liposomes made of archaeal lipids (archaeosomes). These liposomes have several advantages over conventional liposomes, made of phospholipids, 
regarding their preparation, storage conditions, and stability under wide temperature and $\mathrm{pH}$ ranges. Archaeosomes can cross the intact plasma membrane, and when administrated in moderate dosages in vitro or in vivo, they generally do not affect the cell viability or animal physiology. Extensive research has focused on archaeosomes as vaccine delivery systems due to their adjuvant properties, though the delivery of other drugs is also considered [33]-[35]. When drug-carrying archaeosomes enter the targeted cells, electroporation with ns pulses could be used to release the drug.

On the contrary, ns pulses can also exhibit lethal effects on cells and tissues, which could result from DNA and nuclear damage, change in the mitochondrial membrane potential, and/or plasma membrane permeabilization [36]. Namely, ns pulses were reported to induce apoptosis or necrosis in cells in vitro and tumors in vivo [28], [29], [36]-[44]. Whereas treatment with ns pulses appears to be a promising drug-free nonthermal therapy for treating cancer [40], [41], the detrimental effects of ns pulses should be avoided, if we want to use the pulses for drug release from liposomes. For this reason appropriate pulse parameters need to be determined.

In our study, we employed numerical modeling to investigate whether liposome electroporation could be achieved without causing severe damage to the cell and its organelles. Such modeling can also provide us with useful information on how to design the experiments. There are several parameters on which we can influence in experimental settings, such as electric pulse parameters, size of the liposomes, liposome interior conductivity, extracellular medium conductivity, etc. We explored the influence of all these and some other parameters on the ITV and electroporation of the plasma membrane, the nuclear envelope, and membranes of liposomes. By placing the liposomes in various locations inside the cell, we also investigated whether liposomes electroporate differently with respect to their position. Potential risks of ns pulses are discussed and guidelines that might help reduce damaging effects of ns pulses to the cell and its organelles when electroporating liposomes are proposed.

\section{METHODS}

\section{A. Construction of the Model}

The finite-element model of a cell containing the nucleus and intracellular liposomes was constructed in COMSOL Multiphysics 4.2a (COMSOL, Burlington, MA, USA). Most calculations were performed with a 2-D axisymmetric model, which is presented in Fig. 1. The axial symmetry of the geometry allowed us to perform calculations in two dimensions, which considerably reduced the calculation time. However, since the liposome position in this model was confined to the left vertical axis of the model, we also constructed a 3-D model with five differently positioned liposomes, shown in Fig. 2, which allowed us to study the influence of liposome position on their electroporation.

The 2-D model was constructed from a rectangle with dimensions $50 \mu \mathrm{m} \times 100 \mu \mathrm{m}$ representing the extracellular medium, in which a semicircle with radius of $10 \mu \mathrm{m}$ (the cell) was placed. The cell contained a smaller concentric semicircle with radius of

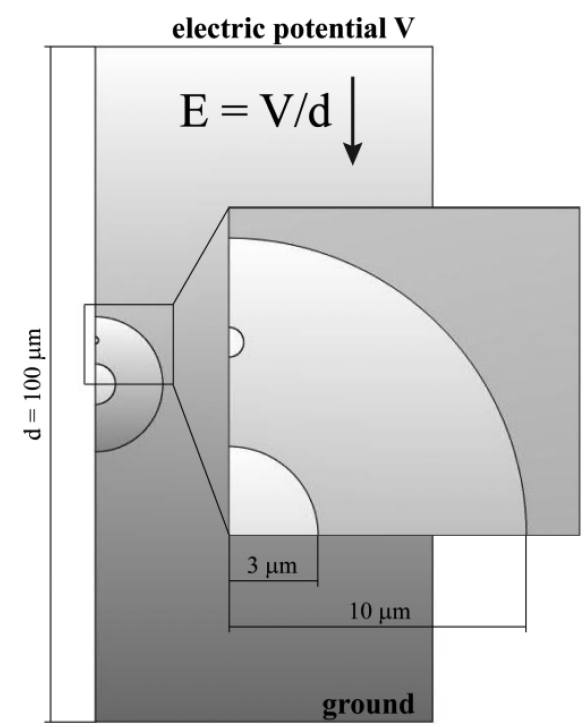

Fig. 1. 2-D axisymmetric model of a cell containing a nucleus and a liposome. The radii of the cell and the nucleus were 10 and $3 \mu \mathrm{m}$, respectively. The radius of the liposome was varied from 50 to $500 \mathrm{~nm}$, with the center of the liposome always positioned in the middle between the nuclear envelope and the plasma membrane. The inset shows enlarged view of the cell, nucleus, and liposome.

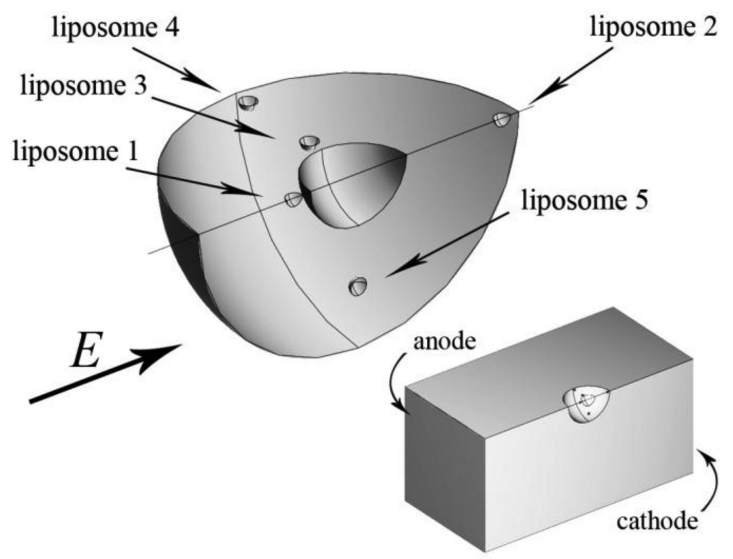

Fig. 2. 3-D model of a cell containing a nucleus and five liposomes. The dimensions of the cell and the nucleus were identical as in Fig. 1. Bottom: The cell was placed in the center of a block representing the extracellular medium. Two opposite sides of the block were modeled as electrodes. Top: Enlarged view of the intracellular position of the liposomes. The distance from the center of the cell to the center of the liposomes is $4 \mu \mathrm{m}$ for liposomes 1 and 3, $9 \mu \mathrm{m}$ for liposomes 2 and 4 , and $6.5 \mu \mathrm{m}$ for liposome 5 .

$3 \mu \mathrm{m}$ representing the nucleus. Another semicircle representing a liposome was positioned in the middle between the plasma membrane and the nuclear envelope with its radius varying between 50 and $500 \mathrm{~nm}$. The boundary condition for the left side of the rectangle was set to Axial Symmetry, the right side was modeled as electrically insulated, whereas the upper and the lower sides of the rectangle were modeled as electrodes by assigning them an electric potential. One electrode was set to ground and the other was excited by a single ns pulse. The pulse was obtained by subtracting two Heaviside functions, one being delayed from the other for $4,10,20$ or $50 \mathrm{~ns}$, using the COMSOL function flclhs. The pulse rise and fall times were set to $1 \mathrm{~ns}$, which is close to the characteristic rise time of some 
nanosecond pulse generators [45], [46]. The pulse duration, to which we refer in this paper, is defined as the pulse width at half maximum amplitude. The pulse amplitude was set to a value resulting in a desired electric field between the electrodes, calculated as the potential difference between the electrodes divided by the electrode distance.

For construction of the 3-D model, spheres, and boxes were used instead of circles and rectangles. Also, the cell contained five differently positioned liposomes with radii of $250 \mathrm{~nm}$. Due to the symmetry of the geometry only a quarter of the complete model was used in calculations (see Fig. 2).

Electric potential $V$ in both the 2-D and 3-D model was calculated in the Electric Currents application mode of the AC/DC module (Time Dependent Study) by

$$
-\nabla\left(\sigma_{i} \nabla V\right)-\nabla \frac{\partial\left(\varepsilon_{i} \nabla V\right)}{\partial t}=0
$$

where $\sigma_{i}$ and $\varepsilon_{i}$ denote the conductivity and dielectric permittivity of a given subdomain, respectively. For each subdomain (extracellular medium, cell, nucleus, and liposomes), a separate application mode of the same type was used, and in each application mode only the corresponding subdomain was activated to calculate $V$ [47], [48].

Plasma membrane, nuclear envelope, and liposome membranes were modeled as the boundary conditions of each of the corresponding application modes by assigning a current density $\boldsymbol{J}$ through the thin shell representing the membrane using Distributed Impedance boundary condition [47], [48]

$$
\boldsymbol{n} \cdot \boldsymbol{J}=\frac{\sigma_{m}}{d_{m}}\left(V-V_{\mathrm{ref}}\right)+\frac{\varepsilon_{m}}{d_{m}}\left(\frac{\partial V}{\partial t}-\frac{\partial V_{\mathrm{ref}}}{\partial t}\right) .
$$

Here, $\boldsymbol{n}$ is the unit vector normal to the surface, $V$ is the electric potential on the interior side of the boundary, $V_{\text {ref }}$ is the potential on the exterior side of the boundary, and $\sigma_{m}, \varepsilon_{m}$, and $d_{m}$, are the membrane conductivity, membrane dielectric permittivity, and membrane thickness, respectively. The ITV is then calculated as the difference between the electric potentials on each side of the boundary.

Cells also have an intrinsic (resting) membrane voltage of few $10 \mathrm{mV}$, with the cell interior being negative relative to its exterior. The ITV superimposes onto this voltage, so that the transmembrane voltage at the anodic pole of the cell is slightly higher compared to the voltage at the opposite pole in its absolute value. A slight asymmetry in membrane electroporation across the two poles can, therefore, appear. However, in our calculations, we neglected the influence of the resting potential, as significant electroporation is expected to occur at considerably higher values $(\sim 1 \mathrm{~V})$ compared to the resting voltage and thus the expected asymmetry in electroporation is small [49].

To model membrane electroporation, we included the asymptotic model of electroporation proposed by DeBruin and Krassowska [49]. Although the model in its basic form does not account for pore expansion, it was found to be particularly appropriate for studies of ns pulses, since it is not expected for the pores to expand significantly on such a short time scale [6]. The dynamics of pore formation is described by differential equation

$$
\frac{\mathrm{d} N}{\mathrm{~d} t}=\alpha \mathrm{e}^{\left(\frac{\mathrm{ITV}}{V_{\mathrm{ep}}}\right)^{2}}\left(1-\frac{N}{N_{0}} \mathrm{e}^{-q\left(\frac{\mathrm{ITV}}{V_{\mathrm{ep}}}\right)^{2}}\right)
$$

where $N$ is the membrane pore density, $N_{0}$ the pore density in the nonelectroporated membrane, and $\alpha, q$, and $V_{\text {ep }}$ are electroporation parameters. This equation was incorporated in the model with the Weak Form Boundary PDE application mode on all surfaces corresponding to the membranes [48].

The increase in the membrane conductivity due to electroporation was determined as follows:

$$
\sigma_{\mathrm{ep}}=\pi r_{p}^{2} \sigma_{p} N \frac{\mathrm{e}^{\nu_{m}}-1}{\frac{w \mathrm{e}^{w-n \nu_{m}}-n \nu_{m}}{w-n \nu_{m}} \mathrm{e}^{\nu_{m}}-\frac{w \mathrm{e}^{w+n \nu m}+n \nu_{m}}{w+n \nu_{m}}} .
$$

Parameters $r_{p}$ and $\sigma_{p}$ are the radius and internal conductivity of a single pore, respectively, and $\nu_{m}$ is the nondimensional transmembrane voltage, given by expression $\nu_{m}=$ $\mathrm{ITV} \cdot F /(R \cdot T)$, where $F$ is the Faraday constant, $R$ is the universal gas constant, and $T$ is the temperature. The expression at the end of (4) accounts for the pore shape and the interactions between the pore wall and ions that are passing through the pore [49], [50]. Assuming a toroidal pore, $n$ is the length of pore entrance area, relative to the membrane thickness. Parameter $w$ is the energy cost for moving an ion from a region of high dielectric constant (water) to a small pore in the lipid bilayer with low dielectric constant. The foundation of the electroporation model is described in detail in [49] and references therein.

The total membrane conductivity $\sigma_{m}$ was calculated at each time step as the sum of the passive membrane conductivity and the conductivity due to electroporation $\sigma_{\mathrm{ep}}$. Equations (1)(4) were solved simultaneously with a linear system solver MUMPS.

\section{B. Parameters of the Model}

In experiments concerning liposome electroporation, some parameters can be varied. Liposomes can be made of different sizes [51], [52] and can be loaded with a medium of arbitrary conductivity. When performing experiments in vitro, the extracellular medium conductivity can also be adjusted. Furthermore, by electroporating the cells with microsecond pulses the conductivity of the plasma membrane can be increased by several orders of magnitude [1], [49] without affecting the membranes of the organelles. If electroporation is performed in a low conductivity medium, the efflux of cytosolic ions reduces the cytoplasmic conductivity [53], [54]. In order to explore, how a change in these parameters could influence the results, we performed calculations for a range of parameter values, given in Table I.

In our calculations, however, we neglected the changes in the extracellular, cytoplasmic, and nucleoplasmic conductivity, which could arise due to electroporation during the pulse application. This is justified since it is not expected for significant transport of ions to occur during an ns pulse because of its extremely short duration [55]. Our results are namely based only on exposure during a single pulse. 
TABLE I

PARAMETERS OF THE MODEL

\begin{tabular}{|c|c|c|c|}
\hline Parameter & Symbol & $\begin{array}{c}\text { Default } \\
\text { value }\end{array}$ & $\begin{array}{l}\text { Range of } \\
\text { values }\end{array}$ \\
\hline Cell radius & $R_{c}(\mu \mathrm{m})$ & $10^{\mathrm{a}}$ & \\
\hline Nuclear radius & $R_{n}(\mu \mathrm{m})$ & $3^{\mathrm{a}}$ & \\
\hline Liposome radius & $R_{\text {lip }}(\mathrm{nm})$ & & $50-500^{i}$ \\
\hline Plasma membrane thickness & $d_{p m}(\mathrm{~nm})$ & $5^{\mathrm{a}}$ & \\
\hline Nuclear envelope thickness & $d_{n e}(\mathrm{~nm})$ & $10^{\mathrm{b}}$ & \\
\hline Liposome membrane thickness & $d_{l m}(\mathrm{~nm})$ & $5^{c}$ & \\
\hline $\begin{array}{l}\text { Extracellular medium } \\
\text { conductivity }\end{array}$ & $\sigma_{e}\left(\mathrm{~S} \cdot \mathrm{m}^{-1}\right)$ & $1.2^{\mathrm{a}}$ & $0.01-1.6^{\mathrm{j}}$ \\
\hline $\begin{array}{l}\text { Extracellular medium } \\
\text { permittivity }\end{array}$ & $\varepsilon_{e}$ & $72.3^{\mathrm{a}}$ & \\
\hline Cytoplasmic conductivity & $\sigma_{c p}\left(\mathrm{~S} \cdot \mathrm{m}^{-1}\right)$ & $0.5^{\mathrm{d}}$ & $0.1-1.3^{\mathrm{e}}$ \\
\hline Cytoplasmic permittivity & $\varepsilon_{c p}$ & $72.3^{\mathrm{a}}$ & \\
\hline Plasma membrane conductivity & $\sigma_{p m}\left(\mathrm{~S} \cdot \mathrm{m}^{-1}\right)$ & $3 \cdot 10^{-7} \mathrm{a}$ & $10^{-10}-10^{-4 \mathrm{~d}}$ \\
\hline Plasma membrane permittivity & $\varepsilon_{p m}$ & $5^{\mathrm{a}}$ & \\
\hline Nucleoplasmic conductivity & $\sigma_{n p}\left(\mathrm{~S} \cdot \mathrm{m}^{-1}\right)$ & $1^{\mathrm{e}}$ & $2 \cdot \sigma_{c p}^{\mathrm{e}}$ \\
\hline Nucleoplasmic permittivity & $\varepsilon_{n p}$ & $72.3^{c}$ & \\
\hline Nuclear envelope conductivity & $\sigma_{n e}\left(\mathrm{~S} \cdot \mathrm{m}^{-1}\right)$ & $1 \cdot 10^{-4 \mathrm{f}}$ & \\
\hline Nuclear envelope permittivity & $\varepsilon_{n e}$ & $10^{\mathrm{g}}$ & \\
\hline Liposome interior conductivity & $\sigma_{l i p}\left(\mathrm{~S} \cdot \mathrm{m}^{-1}\right)$ & $0.5^{\mathrm{c}}$ & $0.01-2^{\mathrm{k}}$ \\
\hline Liposome interior permittivity & $\varepsilon_{\text {lip }}$ & $72.3^{\mathrm{c}}$ & \\
\hline $\begin{array}{l}\text { Liposome membrane } \\
\text { conductivity }\end{array}$ & $\sigma_{l m}\left(\mathrm{~S} \cdot \mathrm{m}^{-1}\right)$ & $3 \cdot 10^{-7} \mathrm{c}$ & \\
\hline Liposome membrane permittivity & $\varepsilon_{l m}$ & $2.1^{\mathrm{h}}$ & $2-5^{\mathrm{k}}$ \\
\hline $\begin{array}{l}\text { Conductivity of aqueous solution } \\
\text { in pores }\end{array}$ & $\sigma_{p}\left(\mathrm{~S} \cdot \mathrm{m}^{-1}\right)$ & $1.3^{\mathrm{d}}$ & \\
\hline Pore radius & $r_{p}(\mathrm{~nm})$ & $0.76^{\mathrm{d}}$ & \\
\hline Relative entrance length of pores & $n$ & $0.15^{\mathrm{d}}$ & \\
\hline Electroporation constant & $q$ & $2.46^{\mathrm{d}}$ & \\
\hline Electroporation parameter & $\alpha\left(\mathrm{m}^{-2} \cdot \mathrm{s}^{-1}\right)$ & $10^{9 \mathrm{~d}}$ & \\
\hline $\begin{array}{l}\text { Characteristic voltage of } \\
\text { electroporation }\end{array}$ & $V_{e p}(\mathrm{~V})$ & $0.258^{\mathrm{d}}$ & \\
\hline Equilibrium pore density & $N_{0}\left(\mathrm{~m}^{-2}\right)$ & $1.5 \cdot 10^{9 \mathrm{~d}}$ & \\
\hline Energy barrier within pore & $w$ & $2.65^{\mathrm{d}}$ & \\
\hline Temperature & $T(\mathrm{~K})$ & $295^{\mathrm{d}}$ & \\
\hline
\end{tabular}

${ }^{\mathrm{a}}$ From [58].

${ }^{\mathrm{b}}$ Set to $2 \cdot d_{p m}$.

${ }^{\mathrm{c}} \mathrm{Set}$ equal to the cytoplasm or the plasma membrane.

${ }^{\mathrm{d}}$ From [49].

${ }^{\mathrm{e}}$ From [54] and [56].

fFrom [57].

${ }^{\mathrm{g}}$ Set between values reported in [56] and [59].

${ }^{\mathrm{h}}$ From [6] and [52].

iFrom [51] and [52].

${ }^{\mathrm{j}}$ From [60] and [61].

${ }^{\mathrm{k}}$ Arbitrary.

According to dielectric spectroscopy measurements of cell electric properties by Polevaya et al. [56] and Garner et al. [54], the ratio between the nucleoplasmic conductivity $\sigma_{\mathrm{np}}$ and the cytoplasmic conductivity $\sigma_{\mathrm{cp}}$ is $\sim 2$, even if the cytoplasmic conductivity reduces due to electroporation in a low conductivity medium [54]. The same ratio was thus kept when $\sigma_{\mathrm{cp}}$ was varied. Although the nuclear envelope is covered with large nuclear pore complexes, experiments have confirmed that the nuclear envelope can actively transport ions [57].

We modeled the nuclear envelope as a boundary condition similarly as the plasma membrane and the liposome membrane. However, the nuclear envelope consists of two membranes separated by a thin perinuclear space filled with electrolyte [57]. For simplicity, we assumed that both membranes have equal electric properties, and that the voltage drop across the perinuclear space is negligible. In this case the voltage equally distributes between both membranes. This allowed us to calculate the ITV across one of the nuclear membranes as half of the ITV across the whole nuclear envelope and apply this value to (3). In short, twice the value of ITV was required for electroporation of the nuclear envelope compared to the plasma membrane or the liposome membrane. Still, in Figs. 3(a) and 5(a), we show only the ITV across one nuclear membrane. The above principle is similar to the one used in [20], where calculations were performed based on a transport lattice approach. The authors modeled the nuclear envelope with three impedances in series; two representing each nuclear membrane and one representing the space between nuclear membranes (we neglected the contribution of the latter).

\section{Comparison of Plasma Membrane, Nuclear Envelope, and Liposome Membrane Electroporation}

The objective of the parametric study was to find such parameters for electroporation of liposomes that would not result in significant electroporation of the plasma membrane or the nuclear envelope. We varied the pulse amplitude at constant pulse duration and calculated the pore density induced over the membranes at the end of the pulse. If a pore density of $N=10^{14}$ $\mathrm{m}^{-2}$ was reached at the pole of a membrane (the point where it was the highest), the membrane was considered to be electroporated (threshold of significant, i.e., observable electroporation). This value was taken from the model of DeBruin and Krassowska [49], which compared simulations with the experiments of Hibino et al. [1]. The pore density of $10^{14} \mathrm{~m}^{-2}$ and higher was also used for presenting the areas of significant membrane electroporation in a similar modeling study [62].

\section{Model Validation}

The time course and spatial distribution of the ITV on the cell membrane and the organelle membrane, if the organelle is positioned in the center of the cell, can be analytically derived using the Laplace equation [58]. The model was validated by comparing the analytical solution for the ITV with numerical calculations obtained in COMSOL Multiphysics. The maximum error for the ITV on the plasma membrane and the organelle membrane (in our case the nuclear envelope or the liposome membranes) was less than $1 \%$ for the 2-D and 3-D model. Therefore, we considered our numerical model to be sufficiently accurate for the calculations performed in our study.

\section{RESULTS}

The model was used to calculate the ITV and the pore density $N$ on the plasma membrane, the nuclear envelope, and the liposome membrane, when the cell is exposed to a single electric pulse of different durations and different amplitudes. A typical example of the time course of ITVs during and shortly after exposure to a $10 \mathrm{~ns}, 50 \mathrm{kV} / \mathrm{cm}$ pulse, as observed at the pole of each membrane, is presented in Fig. 3(a). The first $11 \mathrm{~ns}$ in the figure refer to the time during the pulse (including the pulse rise and fall times) and the next 9 ns to the time after the pulse. 

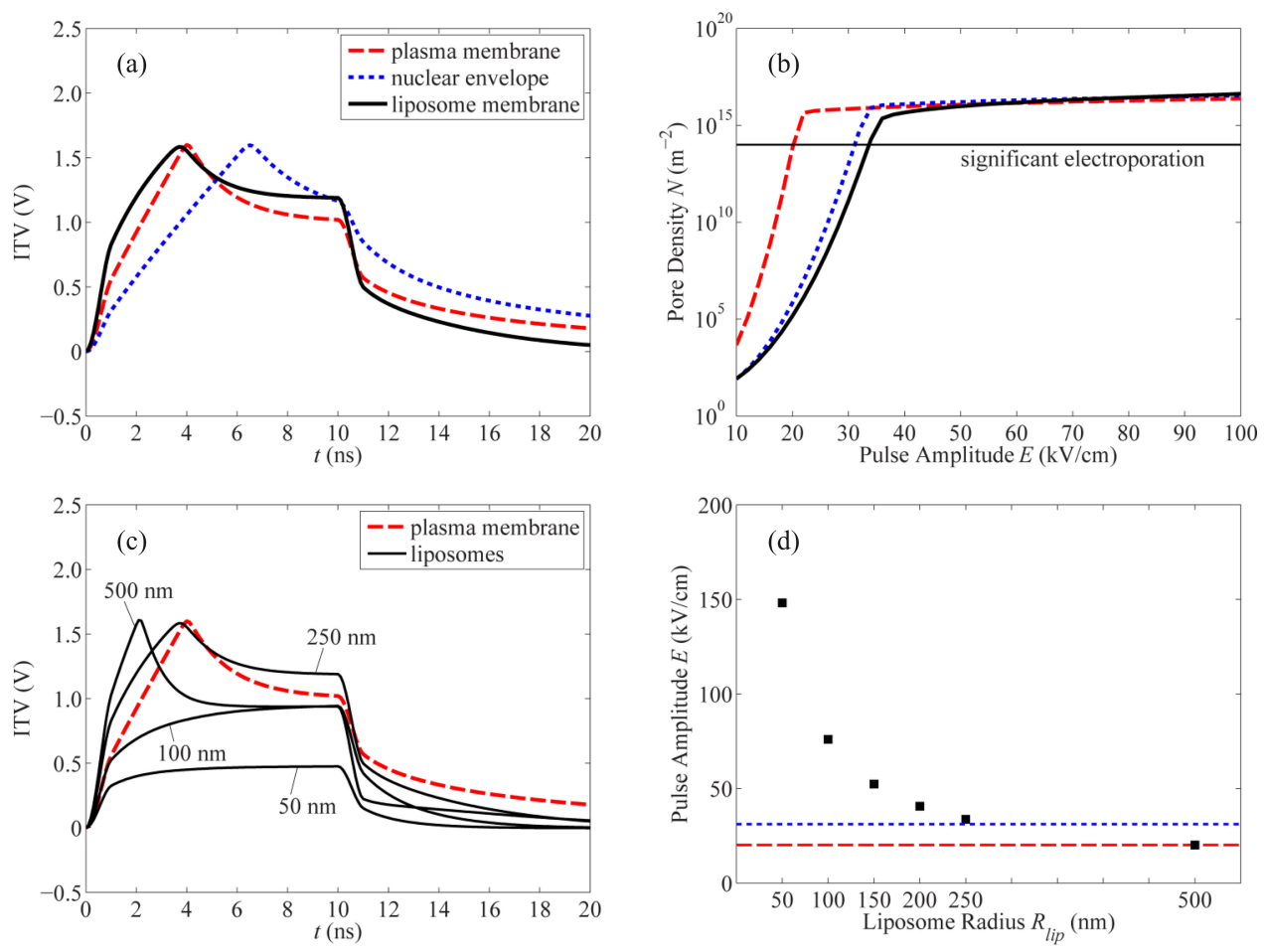

Fig. 3. (a) Time courses of the ITV on the plasma membrane (red dashed line), nuclear envelope (blue dotted line), and liposome membrane (radius 250 nm) (black solid line) for a cell exposed to a $10 \mathrm{~ns}, 50 \mathrm{kV} / \mathrm{cm}$ pulse. The first $11 \mathrm{~ns}$ in the figure refer to the time during the pulse (including the pulse rise and fall times) and the next $9 \mathrm{~ns}$ to the time after the pulse. (b) Pore density $N$, calculated at the membrane poles (the points where the normal to the membrane surface is parallel to the direction of the electric field) at the end of a $10 \mathrm{~ns}$ pulse for a range of amplitudes from 10 to $100 \mathrm{kV} / \mathrm{cm}$. The color code is the same as in (a). The black horizontal line indicates a pore density of $10^{14} \mathrm{~m}^{-2}$, referred to as significant electroporation. (c) Time courses of the ITV for liposomes with radii of 50, 100, 250, and $500 \mathrm{~nm}$. (d) Amplitudes for which the pore density at the liposome pole, depending on the liposome size, reaches significant electroporation at the end of a $10 \mathrm{~ns}$ pulse. The red dashed and blue dotted horizontal lines indicate the pulse amplitudes for significant electroporation of the plasma membrane and the nuclear envelope, respectively.

At the beginning of the pulse, the ITV on the plasma membrane [red dashed line in Fig. 3(a)] and the liposome membrane (black solid line) rise to approximately $1.6 \mathrm{~V}$ in few ns and afterward decrease to a lower value. The decrease in the ITV is due to increase in the pore density in the membranes (electroporation), which considerably increases the membrane conductivity and consequently reduces the voltage drop across the membranes. Similar behavior is observed on the nuclear envelope (blue dotted line).

Fig. 3(b) shows the pore density $N$ at the membrane poles at the end of a $10 \mathrm{~ns}$ pulse for pulse amplitudes in the range from 10 to $100 \mathrm{kV} / \mathrm{cm}$. To obtain this figure, a series of time courses of ITV for pulse amplitudes in steps of $2 \mathrm{kV} / \mathrm{cm}$ were calculated and the values of the pore density at the end of the pulse were extracted. The figure shows that the plasma membrane becomes significantly electroporated (pore density $N$ higher than $10^{14}$ $\mathrm{m}^{-2}$, see Methods) at $20 \mathrm{kV} / \mathrm{cm}$, whereas higher amplitudes, 31 and $34 \mathrm{kV} / \mathrm{cm}$, are needed to electroporate the nucleus and the liposome, respectively.

While Fig. 3(a) and (b) show calculations for a liposome with $250 \mathrm{~nm}$ radius, Fig. 3(c) presents the time courses of the ITV for liposomes with radii of 50, 100, 250, and $500 \mathrm{~nm}$, again for a $10 \mathrm{~ns}, 50 \mathrm{kV} / \mathrm{cm}$ pulse. The ITV on the liposome is strongly affected by its size, namely, the ITV on smaller liposomes is significantly lower than on larger liposomes. As a consequence, higher amplitudes are required for electroporation of smaller liposomes, as demonstrated in Fig. 3(d). The red dashed and blue dotted horizontal lines in Fig. 3(d) indicate the amplitudes for significant plasma membrane and nuclear envelope electroporation, respectively.

We then performed a parametric analysis, where we investigated the influence of the pulse duration and electric properties of the cell and the liposomes on the pulse amplitudes required to obtain electroporation. These amplitudes are presented in Fig. 4 as dots. The range of the parameters was taken from the literature and is also presented in Table I.

A brief look at Fig. 4 shows that the pulse duration mostly affects the amplitudes for the plasma membrane and nuclear envelope electroporation, which are shifted toward lower values with longer pulses, whereas the amplitudes for liposome electroporation are less affected regardless of the liposome size. However, liposomes of different size electroporate at different amplitudes. While the amplitude needed to electroporate a $50 \mathrm{~nm}$ liposome is usually close to or higher than $150 \mathrm{kV} / \mathrm{cm}$, the amplitude for electroporation of a $500 \mathrm{~nm}$ liposome is generally lower than $30 \mathrm{kV} / \mathrm{cm}$.

The amplitudes for plasma membrane, nuclear envelope, and liposome electroporation can, nevertheless, significantly change when varying the values of specific electric parameters. Fig. 4(a)-(d) present the results of calculations for different values of extracellular medium conductivity $\left(\sigma_{e}=0.01-1.6 \mathrm{~S} / \mathrm{m}\right)$. In low conductivity medium, higher amplitudes are required to 

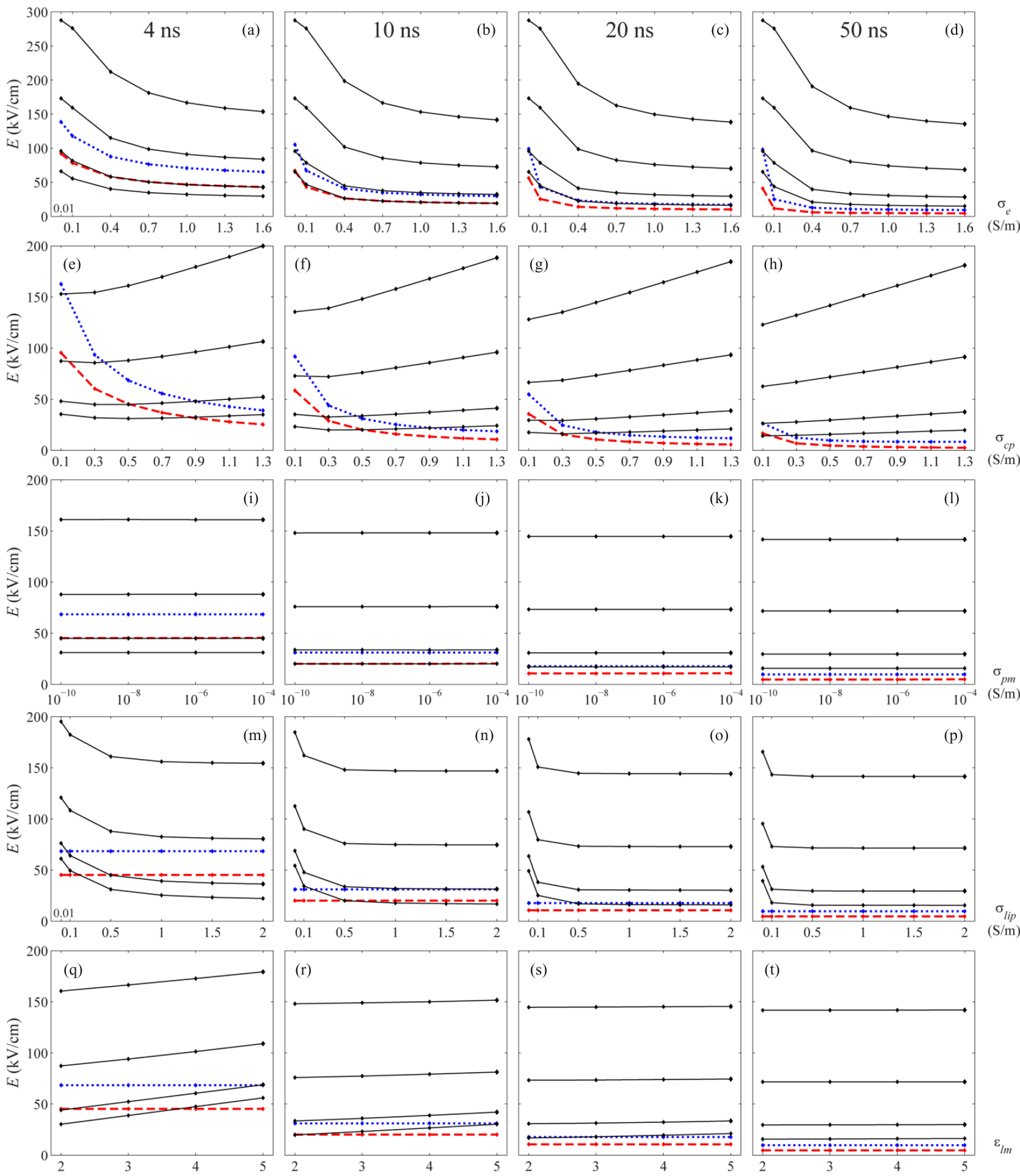

Fig. 4. Amplitudes required for electroporation of the plasma membrane (red dashed line), nuclear envelope (blue dotted line), and liposome membranes (black solid lines). The results are presented for liposomes with radii of 50, 100, 250, and $500 \mathrm{~nm}$. Smaller liposomes are always electroporated at higher amplitudes; thus, the top black solid line refers to the $50 \mathrm{~nm}$ liposome and the bottom line to the $500 \mathrm{~nm}$ liposome. The pulse duration, for which the results were calculated, is indicated on the top of each column (e.g. Fig. (a), (e), (i), (m), and (q) present results for a 4 ns pulse). In each row an individual parameter was varied, while other parameters were kept at their default values (see Table I).

achieve significant electroporation of all membranes, and this is more pronounced for conductivities below $0.7 \mathrm{~S} / \mathrm{m}$.

Fig. 4(e)-(h) show the influence of the cytoplasmic conductivity $\left(\sigma_{\mathrm{cp}}=0.1-1.3 \mathrm{~S} / \mathrm{m}\right)$ on the amplitude for electroporation. We should note that the nucleoplasmic conductivity $\left(\sigma_{\mathrm{np}}\right)$ was also proportionally reduced to obtain a $\sigma_{\mathrm{np}} / \sigma_{\mathrm{cp}}$ ratio of 2 , as explained in Methods. An increase in $\sigma_{\mathrm{cp}}$ considerably decreases the amplitude needed for electroporation of the plasma membrane and the nuclear envelope, and this is more pronounced with shorter pulses. The amplitudes for liposome electroporation 

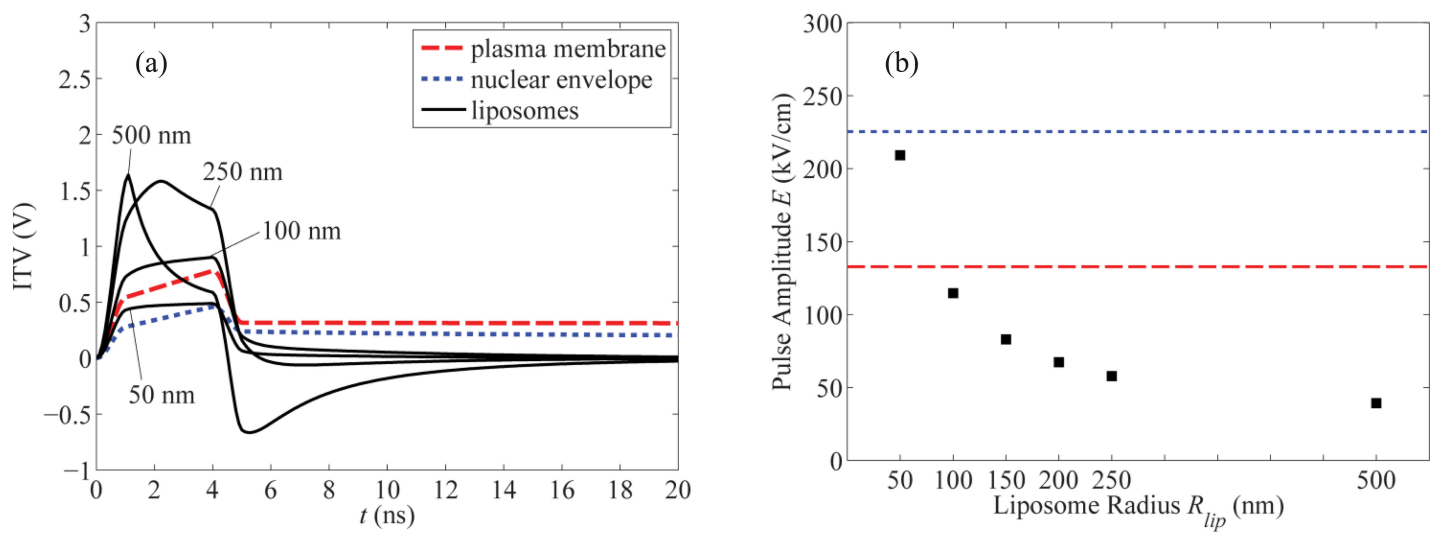

Fig. 5. Calculations for a combination of parameter values that are in favor for liposome electroporation (see text). (a) Time courses of the ITV at the poles of the plasma membrane (red dashed line), nuclear envelope (blue dotted line), and membranes of liposomes with radii of 50, 100, 250, and 500 nm (black solid lines), when the cell is exposed to a $4 \mathrm{~ns}, 70 \mathrm{kV} / \mathrm{cm}$ pulse. (b) Amplitudes for which the pore density at the liposome pole, depending on the liposome size, reaches significant electroporation at the end of a $4 \mathrm{~ns}$ pulse. The red dashed and blue dotted horizontal lines indicate the pulse amplitudes for significant electroporation of the plasma membrane and the nuclear envelope, respectively.

take the opposite direction and increase, though to a smaller extent, with the increase of $\sigma_{\mathrm{cp}}$. This leads to an important observation, namely, that at certain $\sigma_{\mathrm{cp}}$ it is possible to selectively electroporate only liposomes, while the plasma and nuclear membranes remain intact. For example, with 4 ns pulse and with $\sigma_{\mathrm{cp}}=0.1 \mathrm{~S} / \mathrm{m}, 50 \mathrm{kV} / \mathrm{cm}$ pulse would be enough to electroporate 250 and $500 \mathrm{~nm}$ liposomes, while 50 and $100 \mathrm{~nm}$ liposomes, as well as the plasma and nuclear membranes, would remain nonelectroporated.

Fig. 4(i)-(1) present the influence of the plasma membrane conductivity $\left(\sigma_{\mathrm{pm}}=10^{-10}-10^{-4} \mathrm{~S} / \mathrm{m}\right)$. The calculated amplitudes for electroporation are not affected by $\sigma_{\mathrm{pm}}$. Similar can be observed also when changing the liposome membrane conductivity (data not shown). However, the sole effect of the pulse duration on the electroporation amplitudes can be clearly seen. With longer pulses, lower pulse amplitudes are needed to obtain electroporation, but this effect is much more pronounced for the plasma and nuclear membranes.

Fig. 4(m)-(p) show the calculations for different values of the liposome interior conductivity $\left(\sigma_{\text {lip }}=0.01-2 \mathrm{~S} / \mathrm{m}\right)$. This parameter does not impact the amplitude for electroporation of the plasma membrane or the nuclear envelope. In contrast, if liposomes are filled with a more conductive medium, they electroporate at lower amplitudes. The effect of $\sigma_{\text {lip }}$ is greater for shorter pulses (4 and $10 \mathrm{~ns}$ ).

Fig. 4(q)-(t) show the influence of the liposome membrane permittivity $\left(\varepsilon_{\operatorname{lm}}=2-5\right)$. Similar to liposome interior conductivity, this parameter also influences only the amplitudes for electroporation of the liposomes. Liposomes with lower membrane permittivity electroporate at lower amplitudes. Again, the effect of $\varepsilon_{l \mathrm{~m}}$ is greater for shorter pulses (4 and $10 \mathrm{~ns}$ ), whereas for longer pulses (20 and $50 \mathrm{~ns}$ ) it becomes diminished.

The aforementioned parametric analysis demonstrated that some parameters have a considerable impact on plasma membrane, nuclear envelope, and liposome electroporation. Therefore, we performed calculations combining parameter values that are in favor for selective liposome electroporation. These are pulse duration $4 \mathrm{~ns}, \sigma_{\mathrm{cp}}=0.1 \mathrm{~S} / \mathrm{m}, \sigma_{\text {lip }}=2 \mathrm{~S} / \mathrm{m}, \sigma_{\mathrm{pm}}$ $=3 \cdot 10^{-7} \mathrm{~S} / \mathrm{m}$ (parameter was left unchanged as it was shown not to affect the results), and $\varepsilon_{\operatorname{lm}}=2.1$ (parameter was left unchanged as it was already optimal). We also decreased the extracellular medium conductivity to $0.1 \mathrm{~S} / \mathrm{m}$ as incubation of cells in a medium of low ionic strength could result in a decrease of the cytoplasmic conductivity. Results are shown in Fig. 5. Fig. 5(a) presents the time courses of the ITV on the plasma membrane, the nuclear envelope, and liposomes of different sizes for a $4 \mathrm{~ns}, 70 \mathrm{kV} / \mathrm{cm}$ pulse, and Fig. 5(b) presents the amplitudes required for their electroporation. The dots present the amplitudes for electroporation of liposomes, depending on their radius, while the horizontal lines present the amplitudes for electroporation of the plasma membrane (red dashed line) and the nuclear envelope (blue dotted line). Under such conditions, $100 \mathrm{~nm}$ liposomes and larger electroporate at lower amplitudes than the plasma membrane and the nuclear envelope, in contrast to results in Fig. 3(d) where none of the liposomes electroporated below the amplitude for plasma membrane electroporation.

Finally, Fig. 6 presents the influence of the liposome intracellular position on the time courses of the ITV, and pore densities on the plasma membrane and membranes of differently positioned liposomes, when the cell is exposed to a $10 \mathrm{~ns}, 50 \mathrm{kV} / \mathrm{cm}$ pulse. The liposome positioned close to the nuclear pole (liposome 1, see Fig. 2) electroporates at somewhat lower amplitude $(31 \mathrm{kV} / \mathrm{cm})$, while other liposomes electroporate between 34 and $37 \mathrm{kV} / \mathrm{cm}$. Although this indicates that the charging of other larger organelles could affect electroporation of nearby liposomes, most of the liposomes would be electroporated at similar amplitudes.

\section{DiscUSSION}

\section{A. Appropriate Choice of Pulse Parameters for Electroporation of Liposomes (Avoiding the Cytotoxic Effects of Nanosecond Pulses)}

The effects of ns pulses on mammalian cells have been extensively studied in the past decade, since the first experiments performed on human eosinophils showed that ns pulses could electroporate intracellular granules [21]. Subsequent studies further confirmed the initial hypothesis that ns pulses breach 

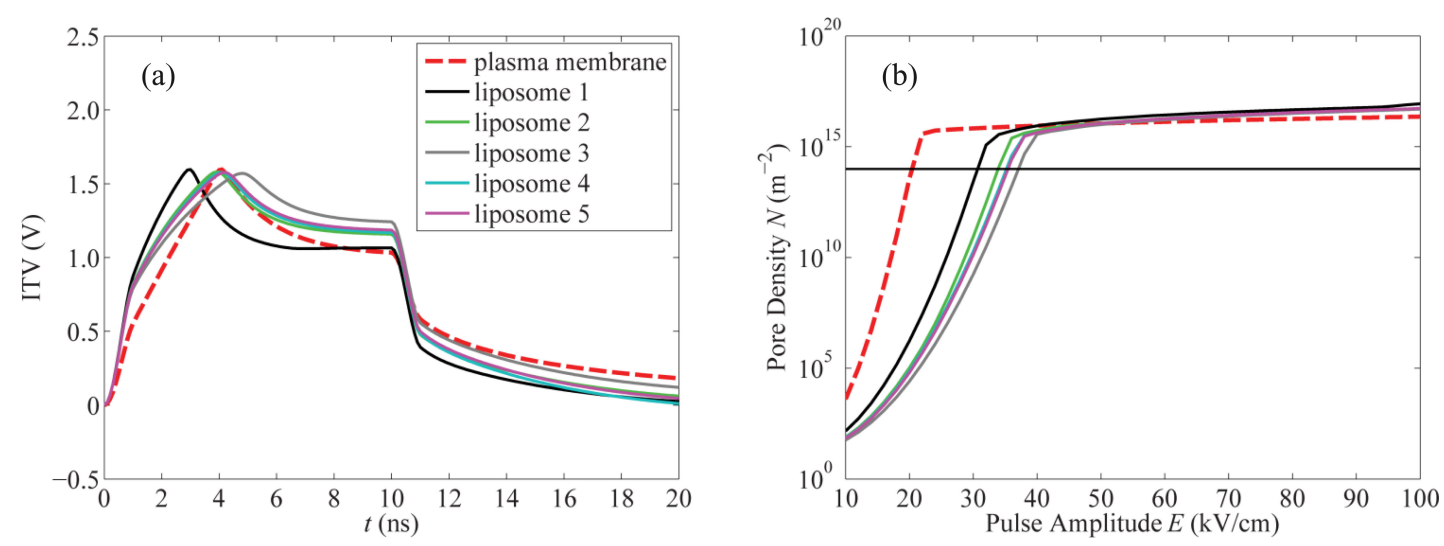

Fig. 6. Influence of the liposome position on liposome electroporation. The arrangement of the liposomes is given in Fig. 2. (a) Time courses of the ITV at the cell and liposome poles for exposure to a $10 \mathrm{~ns}, 50 \mathrm{kV} / \mathrm{cm}$ pulse. (b) Pore density, reached at the cell and liposome poles at the end of a $10 \mathrm{~ns}$ pulse for a range of amplitudes from 10 to $100 \mathrm{kV} / \mathrm{cm}$. The color code is the same as in (a). Horizontal line indicates the pore density for significant electroporation $\left(10^{14} \mathrm{~m}^{-2}\right)$.

the plasma membrane, providing a tool for intracellular manipulation [39]. Beside organelle membrane permeabilization [21]-[28], ns pulses were also shown to cause DNA damage, caspase activation, and induction of apoptosis [28], [36]-[41], [63], [64], or profound plasma membrane damage, following long pulse trains, that eventually lead to cell death by necrosis [29], [42]-[44].

The purpose of our study was to explore the possibility of using ns pulses for electroporation of liposomes preloaded with a specific drug for intracellular drug delivery. Liposomes as a drug delivery system provide protection to its content from degradation and increase the uptake of the drug into the targeted cells. However, when the liposomes enter the cells, their cargo must be released for the drug to become effective. Electroporation of liposomes could present a way to control this release. The main objective of such application is to use pulses that effectively electroporate liposomes but cause as little damage as possible to the cell and other cell organelles. For example, is the liposomes are loaded with specific genes, the cell must remain alive after transfection in order to express these genes. Appropriate choice of pulse parameters is thus of high importance.

Using numerical modeling, we found that it takes about 10 to $20 \mathrm{~ns}$ to fully charge the liposomes considered in our study, which is the reason why the amplitudes for liposome electroporation do not significantly change when the pulses are longer than $10 \mathrm{~ns}$. On the contrary, the cell and the nucleus need more time to charge (since they are larger than liposomes), so they electroporate at considerably lower amplitudes when exposed to a $50 \mathrm{~ns}$ pulse compared to a $10 \mathrm{~ns}$ pulse.

Experimental data indicate that the cytotoxic effects of ns pulses increase with increasing pulse duration and pulse amplitude [28], [29], [36]-[44]. As liposomes would electroporate at similar amplitudes for pulse durations, longer than the charging time of liposomes, pulses with duration equal to or shorter than this charging time ( $\sim 10 \mathrm{~ns})$ should be used for their electroporation. It is also important to note that the amplitude needed for liposome electroporation strongly depends on their size. According to our calculations, liposomes with radius of $500 \mathrm{~nm}$ could be electroporated at $\sim 20 \mathrm{kV} / \mathrm{cm}$, while $50 \mathrm{~nm}$ liposomes require rather high amplitudes, exceeding $150 \mathrm{kV} / \mathrm{cm}$ [see Fig. 3(d) and 4]. When using $10 \mathrm{~ns}$ pulses, electroporation of liposomes, larger than $100 \mathrm{~nm}$, does not seem challenging with respect to retaining the cell viability. This is in agreement with the results of Ibey and coworkers [44], who demonstrated that exposure of cells to a moderate number of $10 \mathrm{~ns}$ pulses with amplitudes of up to $105 \mathrm{kV} / \mathrm{cm}$ does not significantly affect the cell survival. Our results indicate that such liposomes would electroporate below $80 \mathrm{kV} / \mathrm{cm}$. Electroporation of $50 \mathrm{~nm}$ liposomes, however, appears to be more difficult, as these liposomes would electroporate at $\sim 150 \mathrm{kV} / \mathrm{cm}$, which could impact the cell survival more profoundly. Ten pulses with such parameters were already shown to decrease the cell survival to $\sim 50 \%$ in Jurkat cells [43], [44]. Nevertheless, the cytotoxic effects of ns pulses vary between different cell lines [29], [42]-[44], [63], [64] with some indications that adherent cell lines are more resistant compared to cells grown in suspension [63], possibly due to a more complex cytoskeleton network [64]. While $10 \mathrm{~ns}$, $150 \mathrm{kV} / \mathrm{cm}$ pulses were damaging to Jurkat cells, they only negligibly affected the survival of HeLa cells [44]. Therefore, applying $150 \mathrm{kV} / \mathrm{cm}$ pulses may not be detrimental to all cell types [29], [44].

Nevertheless, electroporation with pulses of such high amplitudes would probably also electroporate other larger organelles in the cell interior. We only included the nucleus in our model; however, the endoplasmic reticulum (ER) was also demonstrated as a target of ns pulses. Numerical modeling suggested that observed increases in intracellular calcium levels after ns pulse exposure is due to ER electroporation [20], [65]. Cell death, caused by ns pulse exposure, is dependent on the presence of intracellular calcium, but an increase in the intracellular calcium level itself is not sufficient enough to cause cell death [37]. Namely, intracellular calcium release was detected at pulse amplitudes below observable effect on the cell viability [26]-[28], [37]. The processes, which lead to cell apoptosis, are complex, and it is difficult to predict whether a cell would survive the exposure only based on plasma and organelle membrane electroporation. For this reason, we decided to compare our predicted pulse parameters for liposome electroporation 
with experimental data on cell survival after exposure to pulses of similar parameters, in order to evaluate the possibility of the damaging effects on cells, which could arise from liposome electroporation.

\section{B. Selective Electroporation of Liposomes}

Some early experimental reports on ns pulses implied that cells organelles could be electroporated without disrupting the plasma membrane. Schoenbach et al. [21] reported permeabilization of intracellular granules in human eosinophils after exposure to $3-5$ pulses of $60 \mathrm{~ns}, 36$ and $53 \mathrm{kV} / \mathrm{cm}$, while the plasma membrane remained impermeable to fluorescent dye calcein. Chen et al. [24] showed nuclear membrane permeabilization in HL-60 cells after a single $10 \mathrm{~ns}, 65 \mathrm{kV} / \mathrm{cm}$ pulse, without detectable uptake of propidium iodide (PI) into the cells. Tekle et al. [22] electroporated endocytosed vacuoles in COS-7 cells with one hundred $50 \mathrm{~ns}, 6.7 \mathrm{kV} / \mathrm{cm}$ pulses, while leaving the plasma membrane impermeable to ethidium homodimer.

Although in these experiments plasma membrane electroporation was not detected, modeling studies suggested that pores indeed can form in the plasma membrane, however, they are smaller and appear in larger numbers compared to pores induced by conventional microsecond pulses [6], [20], [58], [62]. This was also confirmed experimentally by showing an increase in plasma membrane conductance using patch-clamp measurements [42], [66], by introducing smaller molecules into the cell (e.g. YO-PRO-1 and $\mathrm{Tl}^{+}$) while plasma membrane remained impermeable to larger molecules (e.g. PI) [67], [68], and by measuring cell volume changes after exposure to ns pulses in the presence of polyethylene glycol and sugar molecules of different sizes [69]. Indeed, two recent studies by Batista Napotnik et al. [23], [25] showed that electroporation of endocytotic vesicles in B16-F1 cells with ten $60 \mathrm{~ns}, 50 \mathrm{kV} / \mathrm{cm}$ pulses, and mitochondrial membrane permeabilization in Jurkat cells with five $4 \mathrm{~ns}, 100 \mathrm{kV} / \mathrm{cm}$ pulses was accompanied by plasma membrane electroporation, detected with PI and YO-PRO-1, respectively.

Nevertheless, a theoretical study by Kotnik and Miklavčič [58] demonstrated that the ITV on the organelle membrane can exceed the ITV on the plasma membrane for some time after the onset of a ns pulse, when the organelle interior conductivity is higher than the cytoplasmic and when the organelle membrane has a lower permittivity or is thicker than the plasma membrane, suggesting that selective electroporation of organelles is possible. If we consider that liposomes are made of pure lipids (membrane permittivity $\sim 2$ ) and that they can be filled with a medium with conductivity substantially higher than the cytoplasmic, liposomes can have the properties required for selective electroporation.

Our results are consistent with these predictions. The model showed that under physiological conditions, selective electroporation is possible for the largest, $500 \mathrm{~nm}$ liposomes, but only when using the shortest, $4 \mathrm{~ns}$ pulses. Despite the fact that liposomes are an order of magnitude smaller than the cell, they charge considerably faster than the plasma membrane due to smaller liposome size and lower liposome membrane permittivity. The size of the $500 \mathrm{~nm}$ liposomes is just enough for their
ITV to notably exceed the ITV on the plasma membrane [see Fig. 3(c)]. Therefore, when applying a sufficiently short pulse, they can be electroporated selectively with respect to the plasma membrane. We must note, though, that the pulse rise time plays and important role. For considerably longer pulse rise times than used in our study (1 ns), exceeding of the liposome ITV above the ITV on the plasma membrane would not be observed.

Our calculations further demonstrated that the selectivity for liposome electroporation could be increased by modifying some of the parameters in the model. When liposomes would be filled with a conductive medium (above $1 \mathrm{~S} / \mathrm{m}$ ), 4 ns pulses could also selectively electroporate $250 \mathrm{~nm}$ liposomes. Adjusting the liposome interior conductivity is not a difficult task, as liposomes can be filled with a medium of arbitrary conductivity in the process of the liposome preparation. Furthermore, a higher liposome interior conductivity might favor electroporation of liposomes before other vesicles, naturally present in the cell (lysosomes, peroxisomes and endosomes), that are comparable in size. We can assume that most of these vesicles have an internal conductivity similar to the cytoplasmic as they are formed in this space. Still, since the size of the liposome/vesicle is an important factor determining the pulse amplitude for electroporation, vesicles considerably larger than liposomes would probably be always electroporated as well.

Furthermore, a reduction in the cytoplasmic conductivity would lower the threshold for electroporation of the liposomes and increase the threshold for electroporation of the plasma membrane and the nuclear envelope, extending the possibility to selectively electroporate even smaller liposomes with even longer pulses (10 ns). In contrast to liposome interior conductivity, the cytoplasmic conductivity is more difficult to manipulate. One option would be incubating the cells in the presence of a low conductivity medium or even moderately electroporate them using classical electroporation protocols, as this causes efflux of ions from the cytoplasm [53]. Similarly, efflux of cytosolic ions could also occur between application of several ns pulses. In this study, we only considered exposure to a single pulse, whereas in practice usually more than one pulse is applied. Although the transport of ions through electroporated membrane during a ns pulse is not expected to be significant due to extremely short pulse duration [55], notable changes in the conductivity could occur between pulses, when ions would have enough time to diffuse through pores. However, since prolonged incubation of cells in a low conductivity medium is not well tolerated by cells [60], the exposure time of the cells outside their growth medium should be minimized.

Liposomes can also be made from different lipids and some can even have protein molecules incorporated into the liposome membrane. This could affect the effective liposome membrane permittivity, which is the reason why we also investigated this parameter. A lower membrane permittivity decreases the charging time, therefore, a liposome composed of pure lipids might be electroporated at lower amplitudes than a similar sized intracellular organelle, which has proteins incorporated in its membrane, but only when 4 or 10 ns pulses are employed.

Nonetheless, the significant variation in results for different values of the cytoplasmic conductivity, liposome interior 
conductivity and liposome membrane permittivity indicate that these parameters should be carefully selected also in numerical modeling.

In addition, we explored the influence of the intracellular liposome position on liposome electroporation. The electric field inside the cell can be locally deformed due to charging of other intracellular organelles. We included the nucleus in our model, which is the largest organelle and could influence the local electric field most profoundly. Indeed, liposome 1, which is positioned close to the nuclear pore, is exposed to somewhat higher electric field compared to other liposomes, and is thus electroporated at lower amplitude. Nevertheless, all liposomes are electroporated in a range of amplitudes from 31 to $37 \mathrm{kV} / \mathrm{cm}$, meaning that their position does not play a major role in electroporation. Consequently, most liposomes of similar size are expected to be electroporated simultaneously and to a similar extent regardless of their position inside the cell.

\section{Validity of the Predicted Thresholds for Electroporation}

The model, which we used in our study, does account for electroporation, but is still very simplistic compared to the complexity of biological cells. It predicts that detectable electroporation occurs when the ITV reaches $\sim 1 \mathrm{~V}$; however, it was found that the electroporation threshold can vary between different cell lines when either microsecond or nanosecond pulses are applied [42], [70]. Still, it was experimentally confirmed that electroporation of the plasma membrane depends on the membrane charging characteristics also with ns pulses [67]. Therefore, the model gives at least important qualitative information on the plasma membrane and organelle membrane electroporation.

We predicted that significant electroporation occurs when a pore density of $10^{14} \mathrm{~m}^{-2}$ is reached in the membrane. One should note, though, that even if we used an order of magnitude lower or higher threshold pore density, in most cases this would not significantly alter the calculated pulse amplitude for electroporation $E$ due to the steep slope of the curve $E(N)$ around $10^{14} \mathrm{~m}^{-2}$ [see Fig. 3(b)].

We assumed that the threshold voltage for liposome electroporation is the same as for the plasma membrane. We calculated the amplitude for electroporation of $50 \mathrm{~nm}$ liposomes to be $\sim 150 \mathrm{kV} / \mathrm{cm}$ when the liposomes are filled with a conductive medium, and $\sim 190 \mathrm{kV} / \mathrm{cm}$, when they are filled with a medium with conductivity of $0.01 \mathrm{~S} / \mathrm{m}$ [exposure to a $10 \mathrm{~ns}$ pulse, Fig. 4(n)]. Tekle et al. [22] exposed salt-filled and sucrosefilled liposomes of similar size (median diameter $103 \mathrm{~nm}$ ) to a single $10 \mathrm{~ns}$ pulse of either 80,160 or $240 \mathrm{kV} / \mathrm{cm}$. They observed that none of the liposomes electroporated at $80 \mathrm{kV} / \mathrm{cm}$, only saltfilled liposomes electroporated at $160 \mathrm{kV} / \mathrm{cm}$, and both salt- and sucrose-filled liposomes electroporated at $240 \mathrm{kV} / \mathrm{cm}$. The liposomes were exposed outside the cell in a low-conductivity sucrose medium, therefore, we cannot directly compare the amplitudes from the experiment with the predicted ones from the model. However, these data qualitatively agree with our calculations and suggest that the predicted amplitudes are not exaggerated.
The parameters, which govern the electroporation process ( $\alpha, q, N_{0}, V_{\mathrm{ep}}$ ) were assumed to be equal for all membranes, although in practice they can differ for membranes of different composition. Considering that the plasma and the organelle membranes are mostly constituted of phospholipids, it can be expected that these parameters are similar for the plasma membrane and the nuclear envelope. On the contrary, liposomes can also be made of archaeal lipids, which have a different structure compared to phospholipids [33], [34], [51]. This difference in structure might affect pore formation. The threshold voltage for electroporation of such archaeosomes has, to our knowledge, not yet been determined, but some preliminary results from planar lipid bilayer experiments and molecular dynamics simulations indicate, that they require a higher ITV for electroporation (unpublished data). In this case, the amplitudes predicted for electroporation by the model would be an underestimate. Furthermore, the liposomes usually enter the cells by endocytosis [31], [32]. This also appears to be true for archaeosomes [35]. If the plasma membrane was still present around the liposome membrane when exposing the cells to ns pulses, the voltage drop across the liposome membrane would be lower, and again, the calculated amplitudes would be an underestimate. Similarly, higher amplitude would also be required to electroporate multilamellar liposomes. All the above indicate that it is important to carefully optimize the experimental protocol in order to avoid the damaging effects of ns pulses, especially when the drug delivery with very small liposomes (up to $200 \mathrm{~nm}$ in diameter) would be unavoidable, e.g., in the case of intravenous administration of liposomes, when liposomes need to be sufficiently small to be able to cross the vascular endothelium wall [32].

\section{CONCLUSION}

Overall, our model suggests two important factors for successful optimization of liposome drug delivery with ns pulses. The first is the pulse duration and the second is the liposome size. Using both shorter pulses and larger liposomes would increase the possibility of selective electroporation of liposomes with respect to other intracellular organelles and the cell itself, and consequently present a smaller risk for compromising the cell viability after the treatment. Liposomes that have a higher internal conductivity and lower membrane permittivity compared to other similar-sized organelles could be favorably electroporated, but only when the pulses are few nanoseconds long.

There is, however, one drawback of using very short pulses for drug delivery. The small size of pores induced by ns pulses ( $\sim 1 \mathrm{~nm}$ [69]), which allows the permeation of only small ions and molecules, could prevent the release of larger molecules or macromolecules (e.g., siRNA) from the liposomes. Nevertheless, a recent experimental study on Chinese hamster lung cells showed that a small population of larger pores may also form in the plasma membrane during exposure to a single $10 \mathrm{~ns}, 40 \mathrm{kV} / \mathrm{cm}$ pulse, which allowed the passage of at least 500 molecules of bleomycin [71]. Furthermore, a single $10 \mathrm{~ns}$ pulse was efficient enough to translocate siRNA into giant unilamellar vesicles [72]. The accompanying molecular dynamics 
simulations demonstrated how a complete translocation of the siRNA molecule can occur on such short time scales.

Based on our calculations and other experimental data, we can conclude that with appropriately adjusted pulse parameters, nanosecond pulses have the potential to be used as a tool for controlled drug release from intracellular liposomes. This study should serve as a guideline for further experiments in this area.

\section{REFERENCES}

[1] M. Hibino, M. Shigemori, H. Itoh, K. Nagayama, and K. Kinosita Jr, "Membrane conductance of an electroporated cell analyzed by submicrosecond imaging of transmembrane potential," Biophys. J., vol. 59, no. 1, pp. 209-220, Jan. 1991

[2] T. Kotnik, G. Pucihar, and D. Miklavčič, "Induced transmembrane voltage and its correlation with electroporation-mediated molecular transport," $J$. Membr. Biol., vol. 236, no. 1, pp. 3-13, Jul. 2010.

[3] T. Y. Tsong, "Electroporation of cell membranes," Biophys. J., vol. 60, no. 2, pp. 297-306, Aug. 1991.

[4] J. Teissié and M. P. Rols, "An experimental evaluation of the critical potential difference inducing cell membrane electropermeabilization," Biophys. J., vol. 65, no. 1, pp. 409-413, Jul. 1993.

[5] E. Neumann, M. Schaefer-Ridder, Y. Wang, and P. H. Hofschneider, "Gene transfer into mouse lyoma cells by electroporation in high electric fields," EMBO J., vol. 1, no. 7, pp. 841-845, 1982.

[6] Z. Vasilkoski, A. T. Esser, T. R. Gowrishankar, and J. C. Weaver, "Membrane electroporation: The absolute rate equation and nanosecond time scale pore creation," Phys. Rev. E, vol. 74, no. 2, pp. 021904-1-02190412, Aug. 2006.

[7] A. A. Gurtovenko, J. Anwar, and I. Vattulainen, "Defect-mediated trafficking across cell membranes: Insights from in silico modeling," Chem. Rev., vol. 110, no. 10, pp. 6077-6103, Oct. 2010.

[8] L. Delemotte and M. Tarek, "Molecular dynamics simulations of lipid membrane electroporation," J. Membr. Biol., vol. 245, no. 9, pp. 531-543, Sep. 2012.

[9] U. Zimmermann, P. Gessner, R. Schnettler, S. Perkins, and S. K. Foung, "Efficient hybridization of mouse-human cell lines by means of hypoosmolar electrofusion," J. Immunol. Methods, vol. 134, no. 1, pp. 43-50, Nov. 1990.

[10] M. Ušaj and M. Kandušer, "The systematic study of the electroporation and electrofusion of B16-F1 and $\mathrm{CHO}$ cells in isotonic and hypotonic buffer," J. Membr. Biol., vol. 245, no. 9, pp. 583-590, Sep. 2012.

[11] R. Heller, M. J. Jaroszeski, D. S. Reintgen, C. A. Puleo, R. C. DeConti, R. A. Gilbert, and L. F. Glass, "Treatment of cutaneous and subcutaneous tumors with electrochemotherapy using intralesional bleomycin," Cancer, vol. 83, no. 1, pp. 148-157, Jul. 1998.

[12] L. M. Mir, J. Gehl, G. Serša, C. G. Collins, J.-R. Garbay, V. Billard, P. F. Geertsen, Z. Rudolf, G. C. O'Sullivan, and M. Marty, "Standard operating procedures of the electrochemotherapy: Instructions for the use of bleomycin or cisplatin administered either systemically or locally and electric pulses delivered by the Cliniporator ${ }^{\mathrm{TM}}$ by means of invasive or non-invasive electrodes," Eur. J. Cancer Suppl., vol. 4, no. 11, pp. 14-25, Nov. 2006.

[13] G. Serša, T. Čufer, S. M. Paulin, M. Čemažar, and M. Snoj, "Electrochemotherapy of chest wall breast cancer recurrence," Cancer Treat. Rev., vol. 38, no. 5, pp. 379-386, Aug. 2012.

[14] J. Teissié, J. M. Escoffre, A. Paganin, S. Chabot, E. Bellard, L. Wasungu, M. P. Rols, and M. Golzio, "Drug delivery by electropulsation: Recent developments in oncology," Int. J. Pharm., vol. 423, no. 1, pp. 3-6, Feb. 2012.

[15] M. Bettan, M. A. Ivanov, L. M. Mir, F. Boissière, P. Delaere, and D. Scherman, "Efficient DNA electrotransfer into tumors," Bioelectrochemistry, vol. 52, no. 1, pp. 83-90, Sep. 2000.

[16] M. Kandušer, D. Miklavčič, and M. Pavlin, "Mechanisms involved in gene electrotransfer using high- and low-voltage pulses-an in vitro study," Bioelectrochemistry, vol. 74, no. 2, pp. 265-271, Feb. 2009.

[17] J. M. Escoffre, T. Portet, C. Favard, J. Teissié, D. S. Dean, and M. P. Rols, "Electromediated formation of DNA complexes with cell membranes and its consequences for gene delivery," Biochim. Biophys. Acta, vol. 1808, no. 6, pp. 1538-1543, Jun. 2011.

[18] N. J. Rowan, S. J. MacGregor, J. G. Anderson, R. A. Fouracre, and O. Farish, "Pulsed electric field inactivation of diarrhoeagenic Bacillus cereus through irreversible electroporation," Lett. Appl. Microbiol., vol. 31, no. 2, pp. 110-114, Aug. 2000.

[19] S. Toepfl, V. Heinz, and D. Knorr, "High intensity pulsed electric fields applied for food preservation," Chem. Eng. Process.: Process Intensif., vol. 46, no. 6, pp. 537-546, Jun. 2007.

[20] T. R. Gowrishankar, A. T. Esser, Z. Vasilkoski, K. C. Smith, and J. C. Weaver, "Microdosimetry for conventional and supra-electroporation in cells with organelles," Biochem. Biophys. Res. Commun., vol. 341, no. 4, pp. 1266-1276, Mar. 2006.

[21] K. H. Schoenbach, S. J. Beebe, and E. S. Buescher, "Intracellular effect of ultrashort electrical pulses," Bioelectromagnetics, vol. 22, no. 6, pp. 440448, Sep. 2001.

[22] E. Tekle, H. Oubrahim, S. M. Dzekunov, J. F. Kolb, K. H. Schoenbach, and P. B. Chock, "Selective field effects on intracellular vacuoles and vesicle membranes with nanosecond electric pulses," Biophys. J., vol. 89, no. 1, pp. 274-284, Jul. 2005.

[23] T. Batista Napotnik, M. Reberšek, T. Kotnik, E. Lebrasseur, G. Cabodevila, and D. Miklavčič, "Electropermeabilization of endocytotic vesicles in B16 F1 mouse melanoma cells," Med. Biol. Eng. Comput., vol. 48, no. 5, pp. 407-413, May 2010.

[24] N. Chen, K. H. Schoenbach, J. F. Kolb, R. J. Swanson, A. L. Garner, J. Yang, R. P. Joshi, and S. J. Beebe, "Leukemic cell intracellular responses to nanosecond electric fields," Biochem. Biophys. Res. Commun., vol. 317, no. 2, pp. 421-427, Apr. 2004.

[25] T. Batista Napotnik, Y. H. Wu, M. A. Gundersen, D. Miklavčič, and P. T. Vernier, "Nanosecond electric pulses cause mitochondrial membrane permeabilization in Jurkat cells," Bioelectromagnetics, vol. 33, no. 3, pp. 257-264, Apr. 2012.

[26] P. T. Vernier, Y. Sun, L. Marcu, S. Salemi, C. M. Craft, and M. A. Gundersen, "Calcium bursts induced by nanosecond electric pulses," Biochem. Biophys. Res. Commun., vol. 310, no. 2, pp. 286-295, Oct. 2003.

[27] S. S. Scarlett, J. A. White, P. F. Blackmore, K. H. Schoenbach, and J. F. Kolb, "Regulation of intracellular calcium concentration by nanosecond pulsed electric fields," Biochim. Biophys. Acta, vol. 1788, no. 5, pp. 1168-1175, May 2009.

[28] S. J. Beebe, J. White, P. F. Blackmore, Y. Deng, K. Somers, and K. H. Schoenbach, "Diverse effects of nanosecond pulsed electric fields on cells and tissues," DNA Cell Biol., vol. 22, no. 12, pp. 785-796, Dec. 2003.

[29] A. G. Pakhomov, A. Phinney, J. Ashmore, K. Walker, J. F. Kolb, S. Kono, K. H. Schoenbach, and M. R. Murphy, "Characterization of the cytotoxic effect of high-intensity, 10-ns duration electrical pulses," IEEE Trans. Plasma Sci., vol. 32, no. 4, pp. 1579-1586, Aug. 2004.

[30] J. Song, R. P. Joshi, and K. H. Schoenbach, "Synergistic effects of local temperature enhancements on cellular responses in the context of highintensity, ultrashort electric pulses," Med. Biol. Eng. Comput., vol. 49, no. 6, pp. 713-718, Jun. 2011.

[31] H. Hillaireau and P. Couvreur, "Nanocarriers' entry into the cell: relevance to drug delivery," Cell. Mol. Life Sci., vol. 66, no. 17, pp. 2873-2896, Sep. 2009.

[32] L. Huang and Y. Liu, "In vivo delivery of RNAi with lipid-based nanoparticles," Аnnu. Rev. Biomed. Eng., vol. 13, pp. 507-530, Aug. 2011.

[33] T. Benvegnu, L. Lemiègre, and S. Cammas-Marion, "New generation of liposomes called archaeosomes based on natural or synthetic archaeal lipids as innovative formulations for drug delivery," Recent. Pat. Drug Del. Formul., vol. 3, no. 3, pp. 206-220, Nov. 2009.

[34] G. B. Patel and W. Chen, "Archaeosomes as drug and vaccine nanodelivery systems," in Nanocarrier Technologies, M. R. Mozafari, Ed. Dordrecht, the Netherlands: Springer-Verlag, 2006, pp. 17-40.

[35] G. D. Sprott, S. Sad, L. P. Fleming, C. J. Dicaire, G. B. Patel, and L. Krishnan, "Archaeosomes varying in lipid composition differ in receptor-mediated endocytosis and differentially adjuvant immune responses to entrapped antigen," Archaea, vol. 1, no. 3, pp. 151-164, Oct. 2003.

[36] S. J. Beebe, P. M. Fox, L. J. Rec, K. Somers, R. H. Stark, and K. H. Schoenbach, "Nanosecond pulsed electric field (nsPEF) effects on cells and tissues: Apoptosis induction and tumor growth inhibition," IEEE Trans. Plasma Sci., vol. 30, no. 1, pp. 286-292, Feb. 2002.

[37] S. Beebe, N. Sain, and W. Ren, "Induction of cell death mechanisms and apoptosis by nanosecond pulsed electric fields (nsPEFs)," Cells, vol. 2, no. 1, pp. 136-162, Mar. 2013.

[38] E. H. Hall, K. H. Schoenbach, and S. J. Beebe, "Nanosecond pulsed electric fields induce apoptosis in p53-wildtype and p53-null HCT116 colon carcinoma cells," Apoptosis, vol. 12, no. 9, pp. 1721-1731, Sep. 2007. 
[39] K. Schoenbach, B. Hargrave, R. Joshi, J. Kolb, R. Nuccitelli, C. Osgood, A. Pakhomov, M. Stacey, R. Swanson, J. White, S. Xiao, J. Zhang, S. Beebe, P. Blackmore, and E. Buescher, "Bioelectric effects of intense nanosecond pulses," IEEE Trans. Dielectr. Electr. Insul., vol. 14, no. 5, pp. 1088-1109, Oct. 2007.

[40] R. Nuccitelli, X. Chen, A. G. Pakhomov, W. H. Baldwin, S. Sheikh, J. L. Pomicter, W. Ren, C. Osgood, R. J. Swanson, J. F. Kolb, S. J. Beebe, and K. H. Schoenbach, "A new pulsed electric field therapy for melanoma disrupts the tumor's blood supply and causes complete remission without recurrence," Int. J. Cancer, vol. 125, no. 2, pp. 438-445, Jul. 2009.

[41] R. Nuccitelli, K. Tran, S. Sheikh, B. Athos, M. Kreis, and P. Nuccitelli, "Optimized nanosecond pulsed electric field therapy can cause murine malignant melanomas to self-destruct with a single treatment," Int. J. Cancer, vol. 127, no. 7, pp. 1727-1736, Oct. 2010.

[42] A. G. Pakhomov, R. Shevin, J. A. White, J. F. Kolb, O. N. Pakhomova, R. P. Joshi, and K. H. Schoenbach, "Membrane permeabilization and cell damage by ultrashort electric field shocks," Arch. Biochem. Biophys., vol. 465, no. 1, pp. 109-118, Sep. 2007.

[43] B. L. Ibey, A. G. Pakhomov, B. W. Gregory, V. A. Khorokhorina, C. C. Roth, M. A. Rassokhin, J. A. Bernhard, G. J. Wilmink, and O. N. Pakhomova, "Selective cytotoxicity of intense nanosecond-duration electric pulses in mammalian cells," Biochim. Biophys. Acta, vol. 1800, no. 11, pp. 1210-1219, Nov. 2010.

[44] B. L. Ibey, C. C. Roth, A. G. Pakhomov, J. A. Bernhard, G. J. Wilmink, and O. N. Pakhomova, "Dose-dependent thresholds of 10-ns electric pulse induced plasma membrane disruption and cytotoxicity in multiple cell lines," PLOS ONE, vol. 6, no. 1, pp. e15642-1-e15642-11, 2011.

[45] J. F. Kolb, S. Kono, and K. H. Schoenbach, "Nanosecond pulsed electric field generators for the study of subcellular effects," Bioelectromagnetics, vol. 27, no. 3, pp. 172-187, Apr. 2006.

[46] J. Sanders, A. Kuthi, Y. H. Wu, P. Vernier, and M. Gundersen, "A linear, single-stage, nanosecond pulse generator for delivering intense electric fields to biological loads," IEEE Trans. Dielectr. Electr. Insul., vol. 16, no. 4, pp. 1048-1054, Aug. 2009.

[47] G. Pucihar, T. Kotnik, B. Valič, and D. Miklavčič, "Numerical determination of transmembrane voltage induced on irregularly shaped cells," Ann. Biomed. Eng., vol. 34, no. 4, pp. 642-652, Apr. 2006.

[48] G. Pucihar, D. Miklavčič, and T. Kotnik, "A time-dependent numerical model of transmembrane voltage inducement and electroporation of irregularly shaped cells," IEEE Trans. Biomed. Eng., vol. 56, no. 5, pp. 14911501, May 2009.

[49] K. A. DeBruin and W. Krassowska, "Modeling electroporation in a single cell. I. Effects Of field strength and rest potential," Biophys. J., vol. 77, no. 3, pp. 1213-1224, Sep. 1999.

[50] R. W. Glaser, S. L. Leikin, L. V. Chernomordik, V. F. Pastushenko, and A. I. Sokirko, "Reversible electrical breakdown of lipid bilayers: Formation and evolution of pores," Biochim. Biophys. Acta, vol. 940, no. 2, pp. 275-287, May 1988.

[51] D. Gmajner, P. Ahlin Grabnar, M. Žnidarič Tušek, J. Štrus, M. Šentjurc, and N. Poklar Ulrih, "Structural characterization of liposomes made of diether archaeal lipids and dipalmitoyl-L- $\alpha$-phosphatidylcholine," Biophys. Chem., vol. 158, no. 2-3, pp. 150-156, Oct. 2011.

[52] A. Di Biasio and C. Cametti, "Dielectric properties of aqueous zwitterionic liposome suspensions," Bioelectrochemistry, vol. 70, no. 2, pp. 328-334, May 2007.

[53] M. Pavlin, M. Kandušer, M. Reberšek, G. Pucihar, F. X. Hart, R. Magjarević, and D. Miklavčič, "Effect of cell electroporation on the conductivity of a cell suspension," Biophys. J., vol. 88, no. 6, pp. 43784390, Jun. 2005.

[54] A. L. Garner, G. Chen, N. Chen, V. Sridhara, J. F. Kolb, R. J. Swanson, S. J. Beebe, R. P. Joshi, and K. H. Schoenbach, "Ultrashort electric pulse induced changes in cellular dielectric properties," Biochem. Biophys. Res. Commun., vol. 362, no. 1, pp. 139-144, Oct. 2007.

[55] K. C. Smith and J. C. Weaver, "Transmembrane molecular transport during versus after extremely large, nanosecond electric pulses," Biochem. Biophys. Res. Commun., vol. 412, no. 1, pp. 8-12, Aug. 2011.

[56] Y. Polevaya, I. Ermolina, M. Schlesinger, B. Z. Ginzburg, and Y. Feldman, "Time domain dielectric spectroscopy study of human cells-Part II: Normal and malignant white blood cells," Biochim. Biophys. Acta, vol. 1419, no. 2, pp. 257-271, Jul. 1999.
[57] M. Mazzanti, J. O. Bustamante, and H. Oberleithner, "Electrical dimension of the nuclear envelope," Physiol. Rev., vol. 81, no. 1, pp. 1-19, Jan. 2001.

[58] T. Kotnik and D. Miklavčič, "Theoretical evaluation of voltage inducement on internal membranes of biological cells exposed to electric fields," Biophys. J., vol. 90, no. 2, pp. 480-491, Jan. 2006.

[59] A. Irimajiri, K. Asami, T. Ichinowatari, and Y. Kinoshita, "Passive electrical properties of the membrane and cytoplasm of cultured rat basophil leukemia cells-Part II: Effects of osmotic perturbation," Biochim. Biophys. Acta, vol. 896, no. 2, pp. 214-223, Jan. 1987.

[60] V. L. Sukhorukov, R. Reuss, D. Zimmermann, C. Held, K. J. Müller M. Kiesel, P. Gessner, A. Steinbach, W. A. Schenk, E. Bamberg, and U. Zimmermann, "Surviving high-intensity field pulses: Strategies for improving robustness and performance of electrotransfection and electrofusion," J. Membr. Biol., vol. 206, no. 3, pp. 187-201, Aug. 2005.

[61] G. Pucihar, T. Kotnik, M. Kandušer, and D. Miklavčič, "The influence of medium conductivity on electropermeabilization and survival of cells in vitro," Bioelectrochemistry, vol. 54, no. 2, pp. 107-115, Nov. 2001.

[62] K. C. Smith and J. C. Weaver, "Active mechanisms are needed to describe cell responses to submicrosecond, megavolt-per-meter pulses: cell models for ultrashort pulses," Biophys. J., vol. 95, no. 4, pp. 1547-1563, Aug. 2008.

[63] M. Stacey, J. Stickley, P. Fox, V. Statler, K. Schoenbach, S. J. Beebe, and S. Buescher, "Differential effects in cells exposed to ultra-short, high intensity electric fields: Cell survival, DNA damage, and cell cycle analysis," Mutat. Res., vol. 542, no. 1-2, pp. 65-75, Dec. 2003.

[64] M. Stacey, P. Fox, S. Buescher, and J. Kolb, "Nanosecond pulsed electric field induced cytoskeleton, nuclear membrane and telomere damage adversely impact cell survival," Bioelectrochemistry, vol. 82, no. 2, pp. 131134, Oct. 2011.

[65] R. P. Joshi, A. Nguyen, V. Sridhara, Q. Hu, R. Nuccitelli, S. J. Beebe, J. Kolb, and K. H. Schoenbach, "Simulations of intracellular calcium release dynamics in response to a high-intensity, ultrashort electric pulse," Phys. Rev. E, vol. 75, no. 4, pp. 041920-1-041920-10, Apr. 2007.

[66] B. L. Ibey, D. G. Mixon, J. A. Payne, A. Bowman, K. Sickendick, G. J. Wilmink, W. P. Roach, and A. G. Pakhomov, "Plasma membrane permeabilization by trains of ultrashort electric pulses," Bioelectrochemistry, vol. 79, no. 1, pp. 114-121, Aug. 2010.

[67] P. T. Vernier, Y. Sun, and M. A. Gundersen, "Nanoelectropulse-driven membrane perturbation and small molecule permeabilization," BMC Cell Biol., vol. 7, pp. 37-1-37-16, 2006.

[68] A. M. Bowman, O. M. Nesin, O. N. Pakhomova, and A. G. Pakhomov "Analysis of plasma membrane integrity by fluorescent detection of $\mathrm{Tl}^{+}$ uptake," J. Membr. Biol., vol. 236, no. 1, pp. 15-26, Jul. 2010.

[69] O. M. Nesin, O. N. Pakhomova, S. Xiao, and A. G. Pakhomov, "Manipulation of cell volume and membrane pore comparison following single cell permeabilization with 60- and 600-ns electric pulses," Biochim. Biophys. Acta, vol. 1808, no. 3, pp. 792-801, Mar. 2011.

[70] M. Čemažar, T. Jarm, D. Miklavčič, A. Maček Lebar, A. Ihan, N. A. Kopitar, and G. Serša, "Effect of electric-field intensity on electropermeabilization and electrosensitivity of various tumor-cell lines in vitro," Electro. Magnetobiol., vol. 17, no. 2, pp. 263-272, Jan. 1998.

[71] A. Silve, I. Leray, and L. M. Mir, "Demonstration of cell membrane permeabilization to medium-sized molecules caused by a single $10 \mathrm{~ns}$ electric pulse," Bioelectrochemistry, vol. 87, pp. 260-264, Oct. 2012.

[72] M. Breton, L. Delemotte, A. Silve, L. M. Mir, and M. Tarek, "Transport of siRNA through lipid membranes driven by nanosecond electric pulses: an experimental and computational study," J. Amer. Chem. Soc., vol. 134, no. 34, pp. 13938-13941, Aug. 2012.

Authors, photographs and biographies not available at the time of publication. 